International Journal of Current Advanced Research

ISSN: O: 2319-6475, ISSN: P: 2319 - 6505, Impact Factor: SJIF: 5.995

Available Online at www.journalijcar.org

Volume 6; Issue 5; May 2017; Page No. 3670-3674

DOI: http://dx.doi.org/10.24327/ijcar.2017.3674.0344

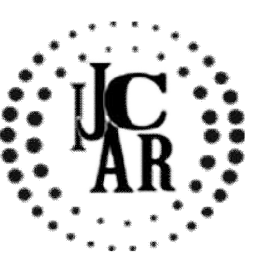

Research Article

\title{
OUR INSTITUTIONAL EXPERIENCE WITH BOWEL SEGMENTS IN BLADDER DISORDERS
}

\author{
R.Gopi Saravanan., K.Saravanan., Govindarajan., \\ R.Jayaganesh and V.Ezhil Sundar
}

Department of Urology Kilpauk Medical College \& Government Royapettah Hospital, Chennai

\section{A R T I C L E I N F O}

\section{Article History:}

Received $15^{\text {th }}$ February, 2017

Received in revised form $24^{\text {th }}$ March, 2017

Accepted $16^{\text {th }}$ April, 2017

Published online $28^{\text {th }}$ May, 2017

\section{Key words:}

Bowel segments, bladder reconstruction, augmentation cystoplasty and ureter transverse colon anastomosis.

\begin{abstract}
A B S T R A C T
Introduction: Reconstructive urologic surgery frequently requires the use of bowel for bladder augmentation. The stomach, jejunum, ileum and colon all have a role in bladder reconstruction (1).

Materials And Methods: Bladder reconstruction with bowel segments was performed in ten patients in our institution between January 2015 to June 2016. We investigated the indications, methods of reconstruction as well as the postoperative complications and clinical outcomes.
\end{abstract}

Results: Out of 10 cases, ureter transverse colon anastomosis was done for carcinoma cervix with post hysterectomy \& post radiotherapy status with vesicovaginal fistulae in 4 patients and augmentation cystoplasty was done for genitourinary tuberculosis in 6 patients.

Conclusion: Usage of bowels in various bladder reconstructive procedures is proved to be safe and effective with minimal morbidity and mortality. Careful patient selection can significantly prolong survival.

Copyright $@ 2017$ R.Gopi Saravanan et al.This is an open access article distributed under the Creative Commons Attribution License, which permits unrestricted use, distribution, and reproduction in any medium, provided the original work is properly cited.

\section{INTRODUCTION}

Bowel is frequently used in reconstructive urological surgery for bladder augmentation and bladder replacement done for various indications (2). Management and care must be tailored according to individual needs. General goals of reconstruction are to protect renal function, minimize infection, and maximize social acceptability. For some patients normal voiding may be a real possibility. However, when not possible, intermittent catheterization may be the next best alternative and may result in dry patients. A clear individualized plan for reconstruction and care must be formulated to fit the particular clinical situation. Before any surgery this plan is presented to the patient and family. The technically best reconstruction in the world is a failure if the patient and support systems cannot comply with the therapeutic plans (3).

\section{MATERIALS AND METHODS}

Analysis of bowel segments in various urological procedures done in our institution between January 2015 \& June 2016 was done. The study included 10 cases of bladder pathologies.

\section{*Corresponding author: R.Gopi Saravanan}

Department of Urology Kilpauk Medical College \& Government

\section{RESULTS}

Age at operation ranged from 31 to 75 years (mean age 53 years). Out of the 10 cases, ureter transverse colon anastomosis was done for carcinoma cervix with post hysterectomy \& post radiotherapy status with vesicovaginal fistulae in 4 patients and augmentation cystoplasty was done for genitourinary tuberculosis in 6 patients. All patients were evaluated with complete blood count, renal parameters, liver function tests, complete urine examination, Urine culture \& sensitivity, urine AFB chest x-ray, USG abdomen and Contrast $\mathrm{CT}$ abdomen \& pelvis.

Counselling regarding risk \& benefits of all procedures was given to all patients. Mechanical bowel preparation was performed with polyethylene glycol solution, and all patients received prophylactic antibiotic treatment during the perioperative period. All cases post operatively were managed by nil per oral, nasogastric tube aspiration, intravenous fluids, maintenance of electrolyte balance, antibiotics \& analgesics. All cases were followed for a period of 10 to 27 months, no death was recorded. Post -operative complications were wound infection in 2 cases, Prolonged ileus in $2 \&$ electrolyte imbalance (hypokalemia) in 3 patients. Midline transperitoneal approach was preferred.

Transverse colon conduit was done based on middle colic arteries, $15 \mathrm{~cm}$ segment is isolated between bowel clamps, and 
a two-layer colocolostomy was performed. The segment is placed caudad to the anastomosis. The ureterocolic anastomoses are then performed by Wallace technique and is anchored to the retroperitoneum close to the midline. The stoma is usually placed in the left upper quadrant. All cases post operatively were managed by nil per oral, naso gastric tube aspiration, intravenous fluids, maintenance of electrolyte balance, antibiotics \& analgesics.Stoma bag was connected,infant feeding tube in the conduit was removed on 14 th post-op day and drain removed when output was less than $50 \mathrm{ml}$, stents were removed after 4 weeks.

For Sigmoid cystoplasty, Fifteen to $20 \mathrm{~cm}$ of sigmoid colon is identified and mobilized. The mesentery is transilluminated to identify the vascular arcade to the segment and ensured that the segment can reach the bladder without tension. The bowel segment is divided between clamps and a colocolostomy performed. The remainder of the abdominal cavity is carefully packed to prevent contamination from the open sigmoid segment. Detubularization and reconfiguration are done. The sigmoid patch is anastomosed to the bivalved bladder. A large suprapubic tube is brought out through the native bladder and secured to the bladder and skin exit sites ureter stent. Drains are placed.

Attention to fluid and electrolyte management (5) and continuous drainage of the bladder was achieved by suprapubic cystostomy. The suprapubic tube was irrigated at least three times daily with sodium bicarbonate solution and whenever drainage was slowed by mucus. Extravesical drains were removed after fifth day. A cystogram was done at 3 weeks, patient was taught clean intermittent catheterization every 2 to 3 hours during the day and one or two times at night after bladder healing was documented. The suprapubic tube was removed after catheterization was successfully under way and well tolerated. The duration between catheterizations was gradually increased during several weeks to 4 to 5 hours during the day $(8,9)$. Postvoid residual volume was checked and advised to continue catheterizations if the residuals was significant.

Follow up was done in all cases, Routine radiographic surveillance of the upper urinary tract was indicated at 6 weeks, 6 months, 1 year and yearly thereafter. Serum electrolyte, blood urea nitrogen, and creatinine determinations along with urine cultures were performed monthly in the first year after surgery.

\section{Complications}

Urine leak: A common complication but was only a temporary problem. Usually resolved on 3rd post operative day noticed in 2 patients.

Bowel related complications: prolonged ileus was noted in 2 patients.

Metabolic complications: Hypokalemia was noted in 3 patients.It was treated with potassium chloride infusion.

Pyelonephritis: noted in 1 patient, treated conservatively with antibiotics.

Renal function: Mild hydroureteronephrosis was noted in 1 patient.

\section{DISCUSSION}

Use of bowels in urology is common, variety of bowel segments were incorporated in different surgeries performed for various indications. In our institute we use bowel for ileal conduit, augmentation cystoplasty \& ureterointestinal anstomosis. In all cases we performed routine investigations, counseling regarding risks \& benefits of incorporation of bowel segment explained to the patients. Mechanical bowel preparation was performed in the usual manner (6), and all patients received prophylactic antibiotic treatment during the perioperative period. All patients have better post operative convalescence and less post-op complications (short term follow up). No deaths were recorded.

We advocated long term antibiotic prophylaxis. To achieve satisfactory results, careful patient selection is essential. It is desirable to have highly motivated patient with realistic expectations and normal intelligence, who are physically and emotionally capable of dealing with strict regimen of CIC so as not to jeopardize the entire procedure.

Bladder augmentation with GI tissue is an important tool in the armamentarium of the urologist in the management of patients with tuberculous bladder with capacity less than $150 \mathrm{ml}$. The goal of augmentation is to create a reservoir with an adequate functional capacity with a low end-filling pressure. By achieving this, the low intravesical pressure will not interfere with ureteral delivery of the urine to the bladder and preserve the upper urinary tract from high pressure damage by vesico-ureteral reflux. Augmentation will alleviate symptoms associated with decreased bladder capacity.

\section{CONCLUSION}

Various segments of bowel were advocated in different urological surgeries with minimal complications.Mechanical bowel preparation, perioperative antibiotics and fine suturing techniques lead to decrease in complication rate. Ureter transverse colon anastomosis is an ideal treatment option for vesicovaginal fistula in a cervical cancer patient,previously treated with radiation as the small bowel would have been affected by radiation. Augmentation cystoplasty offers a successful long-term solution for patients with small contracted bladder (capacity $<150 \mathrm{ml}$ ), causing bothersome symptoms - a sequelae of genitourinary tuberculosis. It improves symptoms \& prevents renal deterioration.If done for proper indications, the procedure is well tolerated resulting in gratifying long-term outcomes.

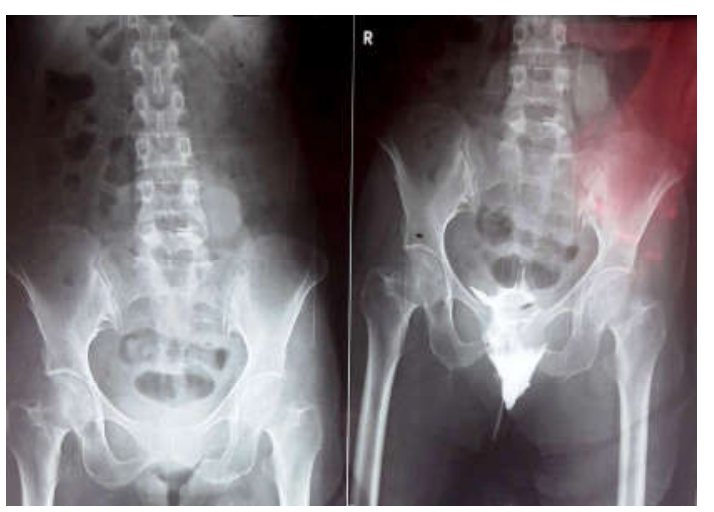

Figure 1 cystogram picture of vesicovaginal fistula in posthysterectomy \& post radiation status 


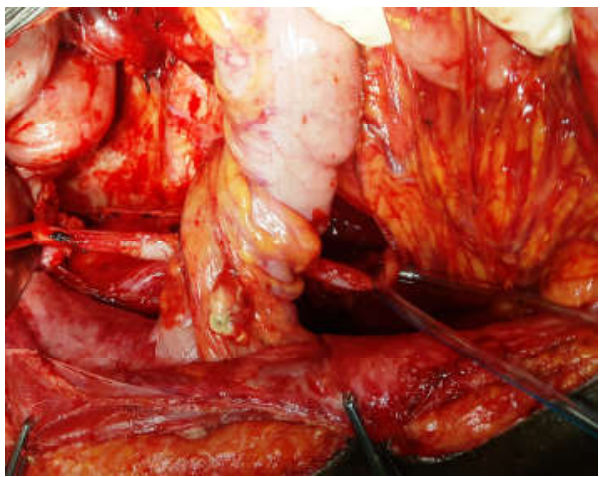

Fig.2 left ureter being dissected with its intact vascular supply

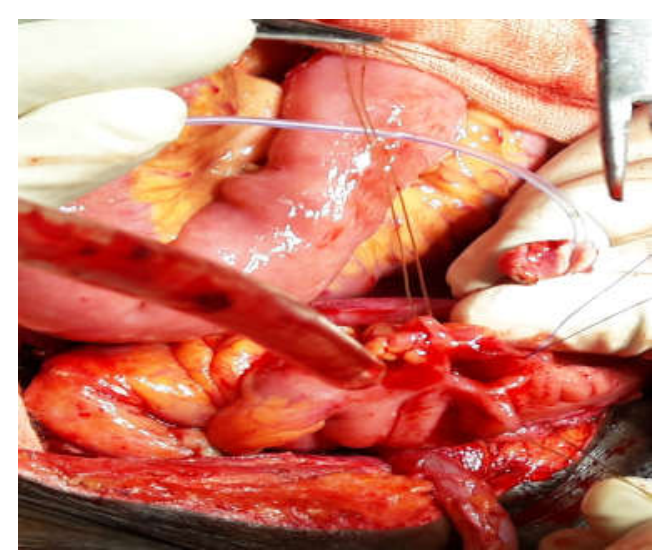

Fig.3 Transverse Colon Being Opened Along Its Taenia Coli

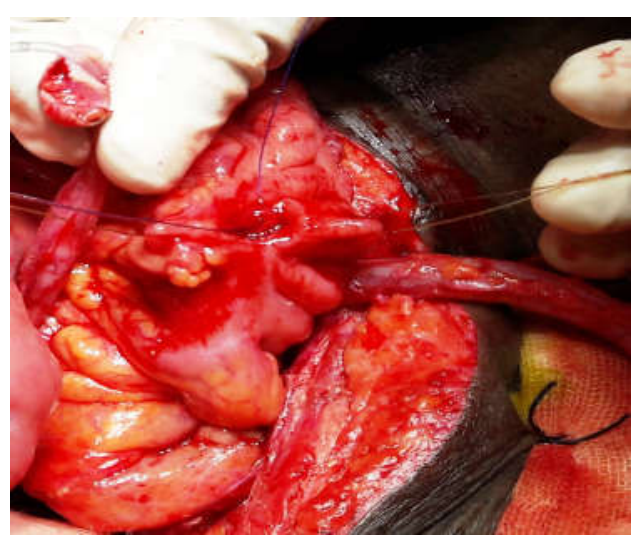

Fig.4 ureter being anastomosed to transverse colon

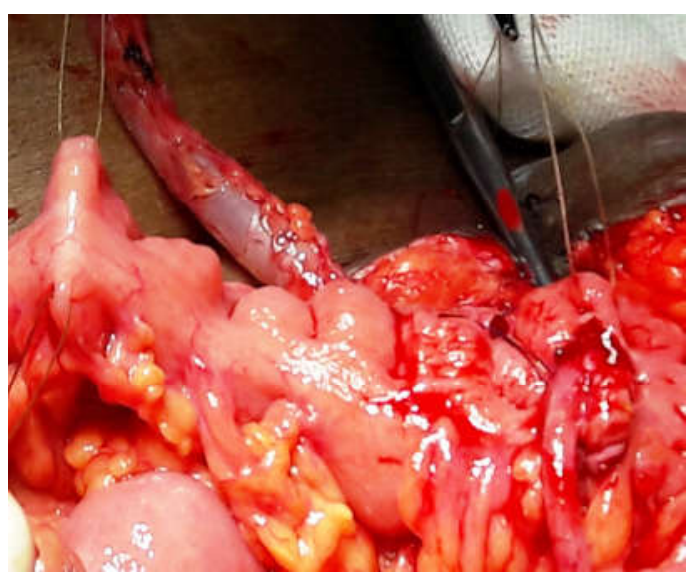

Fig.5 one side ureter transverse colon anastomosis completed

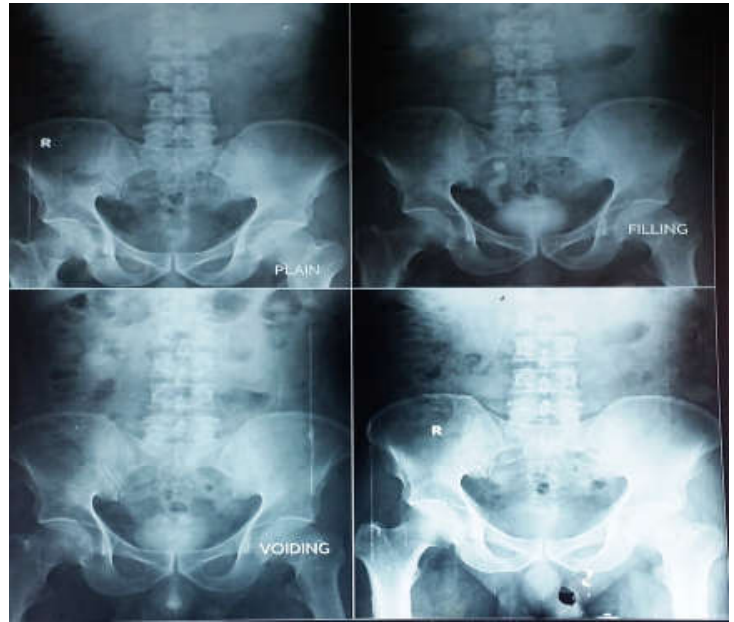

Fig.6 Micturating cystourethrogram of GUTB patient showing contracted bladder

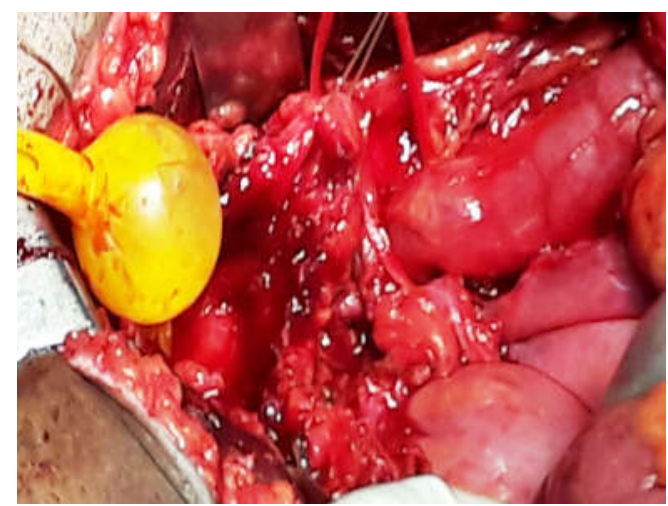

Fig.7 Contracted Bladder After Getting Bivalved

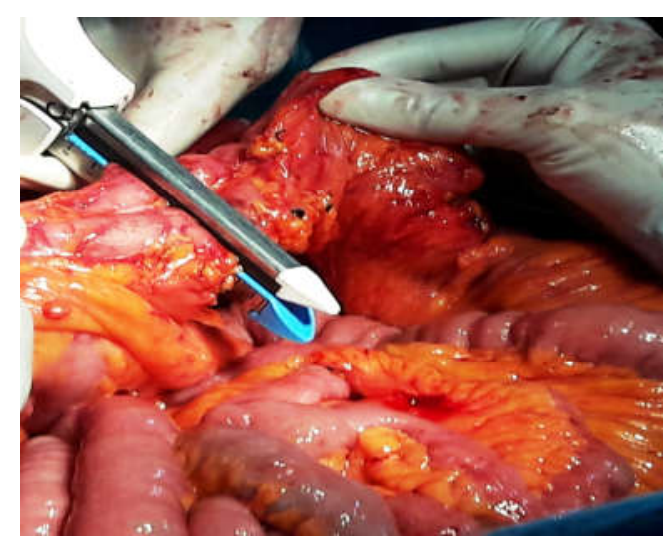

Fig.8 sigmoid colon being divided with bowel stapler

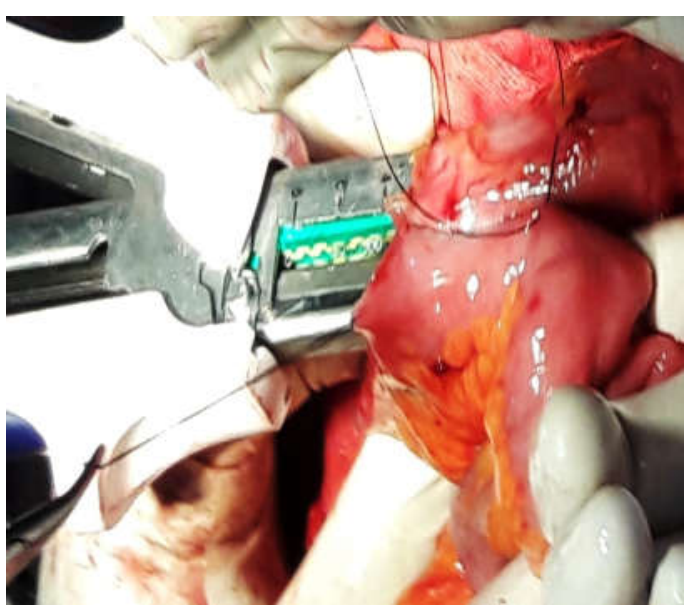

Fig.9 colocolostomy being performed with anastomotic bowel stapler 


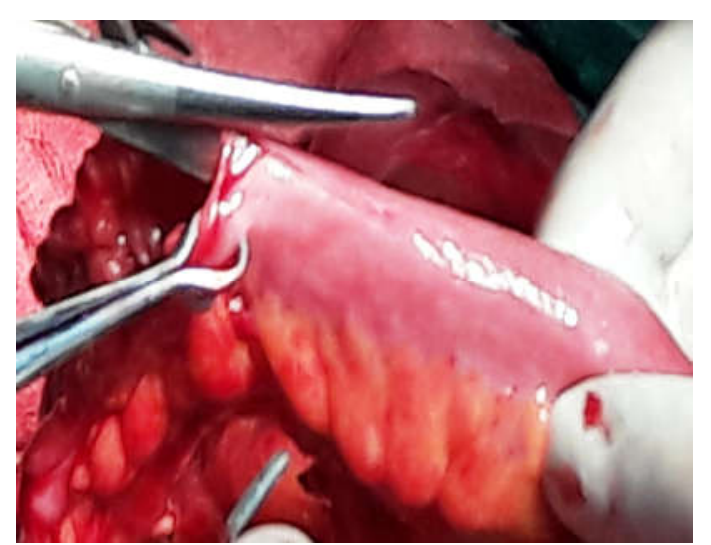

Fig.10 colon being opened along its antimesenteric border

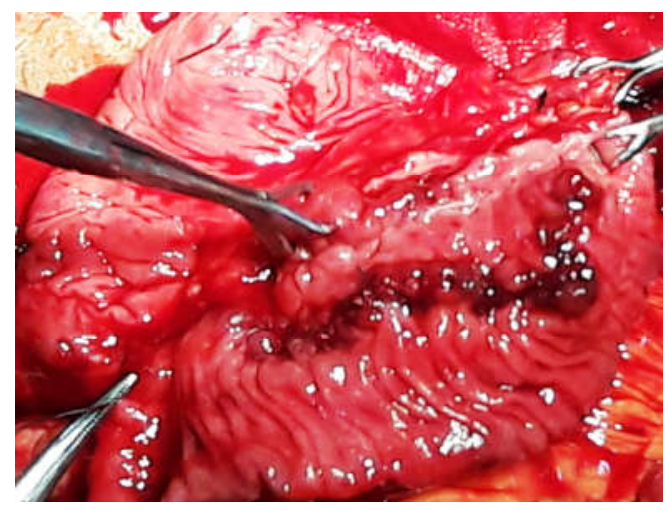

Fig.10 detubularisation of bowel segment being done

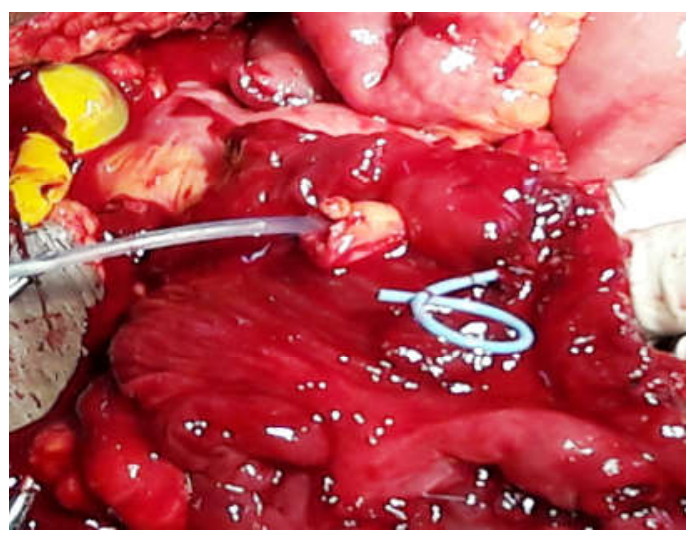

Fig.11 ureter being anastomosed to detubularised bowel segment

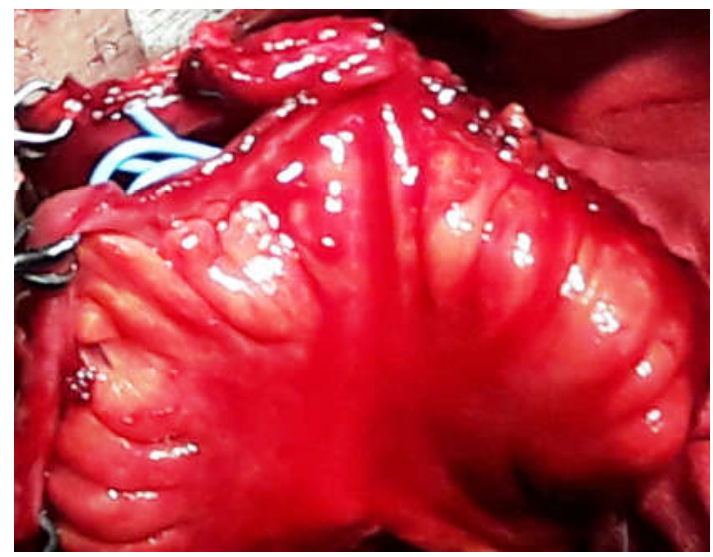

Fig.12 sigmoid cystoplasty getting completed

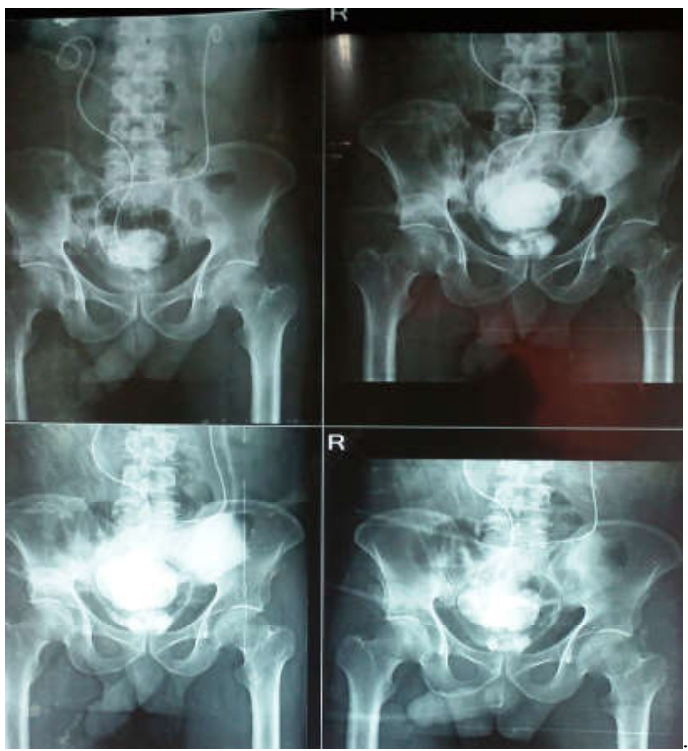

Fig.13 postoperative cystogram showing widened bladder capacity

\section{References}

1. Adams MC et al, Gastrocystoplasty. An alternative solution to the problem ofurological reconstruction in the severely compromised patient. J Urol 1988; 140:1152-6

2. Campbell walsh urology 11 th edition

3. Historical perspective of the use of bowel in urology Urologic Clinics of North America, Volume 24, Issue 4, Pages 703-713.

4. Goodwin et al, Cup-patch technique of ileocystoplasty for bladder enlargement or partial substitution. Surg Gynecol Obstet 1959; 108:240-4.

5. Gilbert SM, Hensle TW. Metabolic consequences and long term complications of enterocystoplasty in children: A review. J Urol 2005; 173:1080-6.

6. Guenaga K, Matos D, Castro A, et al. Mechanical bowel preparation for elective colorectal surgery. Cochrane Database Syst Rev 2005; CD001544.

7. Gillen water adult and pediatric urology 4 th edition

8. Lapides $\mathrm{J}$ et al, Clean intermittent selfcatheterization in the treatment of urinary tract disease. J Urol 972; 107:458-61.

9. Long-term effects of urinary diversion: a comparison of myelomeningocele patients managed by clean, intermittent catheterization and urinary diversion. $J$ Urol 1992; 147:1343-7.

10. Metabolic alterations at different levels of renal function following continent urinary diversion through colonic segments. J Urol 1997; 157:2099103.

11. Metabolic complications of urinary intestinal diversion. J Urol 1992; 147:1199-208.

12. Mundy AR et al, ileocystoplasty for the treatment of refractory urge incontinence, $\mathrm{Br} J$ Urol 1985; 57:641-6

13. Nichols RL et al., Efficacy of preoperative antimicrobial preparation of the bowel. Ann Surg 1972; 176:227-32.

14. Snow BW, Cartwright PC. Bladder autoaugmentation. Urol Clin North Am 1996; 23:323 
15. The Kelalis-King-BelmanTextbook of Clinical Pediatric Urology Fifth edition Winter CC, Goodwin WE. Results of sigmoidocystoplasty. J Urol 1958; 80:467-72.

\section{How to cite this article:}

R.Gopi Saravanan et al (2017) ' Our Institutional Experience With Bowel Segments In Bladder Disorders', International Journal of Current Advanced Research, 06(05), pp. 3670-3674.

DOI: http://dx.doi.org/10.24327/ijcar.2017.3674.0344 